\title{
Outbreak of NDM-1-producing Enterobacteriaceae in northern Italy, July to August 2011
}

P Gaibani ${ }^{1,2}$, S Ambretti ${ }^{1,2}$, A Berlingeri ${ }^{1}$, M Cordovana ${ }^{1}$, P Farruggia ${ }^{3}$, M Panico $^{3}$, M P Landini $^{1}$, V Sambri (vittorio.sambri@unibo.it) ${ }^{1}$

1. Operative Unit of Clinical Microbiology, S. Orsola-Malpighi University Hospital, Bologna, Italy

2. These authors contributed equally to this paper

3. Bellaria Hospital, Bologna, Italy

Citation style for this article:

Gaibani P, Ambretti S, Berlingeri A, Cordovana M, Farruggia P, Panico M, Landini MP, Sambri V. Outbreak of NDM-1-producing Enterobacteriaceae in northern Italy, July to August 2011.

uro Surveill. 2011;16(47):pii=20027. Available online: http://www.eurosurveillance.org/ViewArticle.aspx?Articleld=20027

Article published on 24 November 2011

Between July 2011 and August 2011, the New Delhi metallo-beta-lactamase 1 (NDM-1) gene was detected in Klebsiella pneumoniae and Escherichia coli isolates obtained from six patients hospitalised in four healthcare facilities in northern Italy. The patient who had been hospitalised in New Delhi, India, from February to May 2011 and subsequently in the Bologna area, Italy, from May to July 2011, may have been the source of the outbreak. Our findings suggest ongoing spread of this carbapenem-resistance gene in Italy and highlight the need for intensive surveillance.

\section{Outbreak description}

On 2 July 2011, we isolated Klebsiella pneumoniae harbouring the New Delhi metallo-beta-lactamase gene $\left(\right.$ bla $\left.a_{\mathrm{NDM}}\right)$, cultured from the urine of a patient (Patient 1) who was admitted to a nursing home (Facility $A$ ), in Bologna, Italy. In the same period, two bla $a_{\mathrm{NDM}}$ positive $K$. pneumoniae isolates were identified in patients in two hospitals (Facilities $B$ and $C$ ) in the Bologna area on 8 July (Patient 2) and 13 July (Patient 3), respectively. Patient 2 had been previously admitted to the same nursing home (Facility A) as Patient 1. Subsequently, two further bla $a_{\mathrm{NDM}}$-positive K. pneumoniae isolates were identified on 18 and 22 July from Patients 4 and 5 , respectively, who were in the same nursing home as Patient 1 . Retrospective analysis of the hospital records indicated a possible epidemiological link between Patients 1, 2, 4 and 5 since the timing of the stays of Patients 2, 4 and 5 in healthcare facilities overlapped with that of Patient 1 (from June to July 2011) and four of these five patients (Patients 1, 2, 4 and 5) had been admitted to the same nursing home. Patient 3 had been in the same hospital (Facility C) as Patient 1 in the second week of July.

In addition, an Escherichia coli harbouring bla ${ }_{\mathrm{NDM}}$ was isolated on 8 August from a patient (Patient 6) who was hospitalised in a fourth facility, a tertiary hospital (Facility D) in the same geographical area. Epidemiological investigations suggested that this patient was probably the source of the outbreak: this patient had been hospitalised from February to May 2011 in New Delhi, India, and then, after arriving in Italy, in a fifth facility (Facility E) from 25 May to 11 July. During the stay in Facility $E$ and before the detection of an NDM-producing $E$. coli in August, $E$. coli had been cultured from four urine samples (the first on 26 May). These isolates showed an elevated level of resistance to carbapenems: the antimicrobial susceptibility of these four isolates was very similar to that of the isolate bearing NDM that we subsequently isolated. Unfortunately, we did not have the opportunity to test for the presence of NDM in these first four isolates from this patient, as this routine diagnosis was carried out in another laboratory. It should be noted that the culture from the fourth sample also led to the isolation of a $K$. pneumoniae strain with reduced susceptibility to carbapenems.

It is noteworthy that Patients 1 to 5 had no reported history of travel to or hospitalisation in an NDM-1 endemic area. It was not possible to identify a direct epidemiological link between Patient 6 and the other five patients. Patient 6 had been hospitalised in the same hospital (Facility C) as two other patients in this outbreak (Patients 1 and 3). From the information currently available, it is not possible to identify a possible link between Patient 6 and Patients 2, 4 and 5 .

The dates of the stays of Patients 1-6 in the healthcare facilities are shown in the Table.

\section{Background}

Carbapenems are the preferred treatment for severe infections caused by multidrug-resistant Gramnegative bacteria producing an extended-spectrum beta-lactamase (ESBL). For this reason, the increasing and rapid spread of mobile genetic elements that determine acquired resistance to carbapenems and all other beta-lactams in Enterobacteriaceae [1] is of great concern. In the last few years, the considerable spread of carbapenem-resistant $K$. pneumoniae strains harbouring the $K$. pneumoniae carbapenemase (KPC) 
gene $\left(b / a_{\mathrm{KPC}}\right)$ has been reported in Europe [2] and has greatly affected Italy [3,4].

Recently, an increase in the spread of a novel acquired carbapenemase, New Delhi metallo-betalactamase 1 (NDM-1), which can be produced by several Enterobacteriaceae species, has been reported in Europe: a total of 77 cases were reported from 13 countries from 2008 to 2010 [2]. In Italy, NDM-1-positive isolates were first described earlier this year [5]: NDM1-positive $E$. coli was found in a patient with an indirect epidemiological link to NDM-1-endemic areas. Transient colonisation was apparently seen in another patient linked to the index case.

\section{Laboratory investigations}

The carbapenem-resistant strains were collected from four different Italian healthcare facilities in the Bologna area. Routine determination of minimum inhibitory concentrations (MICs) was performed by using a VITEK2 automated system (bioMérieux, France) and the results were interpreted according to the European Committee on Antimicrobial Susceptibility Testing [EUCAST] guidelines [6]. Isolates that showed reduced susceptibility to ertapenem $(\geq 0.5 \mathrm{mg} / \mathrm{L})$ were further evaluated in order to investigate the mechanism of resistance. This phenotype is thought to arise from the production of carbapenemase or metallo-beta-lactamase (MBL) or ESBL associated with porin loss. As a phenotypic confirmatory test for carbapenemase production, the modified Hodge test [7] and a disc-diffusion synergy test (ROSCO Diagnostica, Denmark) were performed.

Between 1 March and 30 August 2011, a total of 44 Enterobacteriaceae isolates that showed reduced susceptibility to carbapenems and in which the $b a_{\text {KPC }}$ gene was not detected were screened for the presence of an
MBL-resistance mechanism. The disc-diffusion synergy test indicated MBL production (inhibition of carbapenemase activity by dipicolinic acid) for the six isolates (five K. pneumoniae and one E. coli).

Polymerase chain reaction (PCR) amplification of the bla $a_{\mathrm{NDM}-1}$ gene and direct cloning and sequencing of the PCR product was performed as previously described [8]. The sequences obtained were compared using BLAST (basic local alignment search tool) [9]. In accordance with the phenotypic results, this molecular testing confirmed the presence of the $b / a_{\mathrm{NDM}-1}$ gene in all six isolates, with $99.9 \%$ identity with $b^{M} a_{\mathrm{NDM}-1}$ gene present in GenBank (JF714412.1). In addition, all the isolates contained the bla $a_{\mathrm{TEM}-1}$ gene.

The six $b l a_{\mathrm{NDM}}$-positive isolates showed MICs of $>8$ $\mu \mathrm{g} / \mathrm{mL}$ for ertapenem, while for imipenem, the MICs ranged from $<1$ to $>32 \mu \mathrm{g} / \mathrm{mL}$ and for meropenem from 2 to $4 \mu \mathrm{g} / \mathrm{mL}$. Furthermore, they had a high resistance rate to other classes of antimicrobials, such as fluoroquinolones and aminoglyocosides. The only drugs that showed a good level of antimicrobial activity against all six isolates in vitro were tigecycline and colistin, with $\mathrm{MICs}$ of $\leq 2 \mu \mathrm{g} / \mathrm{mL}$ and $\leq 1 \mu \mathrm{g} / \mathrm{mL}$, respectively. The antimicrobial susceptibility profiles of the six isolates are listed in the Table.

\section{Discussion}

After the first identification of NDM-production in $K$. pneumoniae and $E$. coli isolates in a Swedish patient of Indian origin in 2009, NDM has been detected in all continents [10]. Enterobacteriaceae that carry carbapenemase-producing genes, including $b a_{\mathrm{NDM}}$ and $b l a_{\mathrm{KPC}}$, are considered an important public health problem because of ability of these genes to spread [1] and the considerable clinical impact of this type of

\section{TABLE}

Minimum inhibitory concentration of selected antimicrobial agents against NDM-1-producing Enterobacteriaceae isolates, northern Italy, July-August 2011

\begin{tabular}{|c|c|c|c|c|c|c|c|c|c|c|c|c|c|c|c|c|c|c|}
\hline \multirow[b]{2}{*}{ Patient } & \multirow{2}{*}{$\begin{array}{l}\text { Sample } \\
\text { collection } \\
\text { date } \\
(2011)\end{array}$} & \multirow[b]{2}{*}{$\begin{array}{l}\text { Patient's } \\
\text { healthcare } \\
\text { facility }\end{array}$} & \multirow{2}{*}{$\begin{array}{c}\text { Dates of stay } \\
\text { in healthcare } \\
\text { facility } \\
(2011)\end{array}$} & \multirow[b]{2}{*}{ Isolate } & \multirow[b]{2}{*}{ Sample } & \multicolumn{13}{|c|}{ Minimum inhibitory concentration $(\mu \mathrm{g} / \mathrm{mL})$} \\
\hline & & & & & & AK & AMC & CAZ & CIP & $\mathrm{CL}$ & EPM & IPM & MPM & GM & TZP & TYG & SXT & СTX \\
\hline 1 & 2 Jul & $\begin{array}{l}\text { A } \\
\text { C }\end{array}$ & $\begin{array}{c}1 \text { Jul-12Jul } \\
12 \text { Jul }-20 \text { Jul }\end{array}$ & $\begin{array}{c}\text { Klebsiella } \\
\text { pneumoniae }\end{array}$ & Urine & 16 & $>32$ & $>64$ & $>4$ & 0.5 & $>8$ & $\leq 1$ & 2 & 16 & $>128$ & 1 & $>320$ & $>64$ \\
\hline 2 & $8 \mathrm{Jul}$ & $\begin{array}{l}\text { A } \\
B\end{array}$ & $\begin{array}{l}\text { 21 Jun-4Jul } \\
4 \text { Jul-20 Sep }\end{array}$ & $\begin{array}{c}\text { K. } \\
\text { pneumoniae }\end{array}$ & Bile & 16 & 132 & $>64$ & $>4$ & 1 & $>8$ & $\leq 1$ & 4 & 16 & $>128$ & 2 & 20 & $>64$ \\
\hline 3 & $13 \mathrm{Jul}$ & C & 7 Jun-27 Jul & $\begin{array}{c}\text { K. } \\
\text { pneumoniae }\end{array}$ & Sputum & 2 & 132 & $>64$ & $>4$ & 0.5 & $>8$ & 4 & 2 & 8 & $>128$ & 1 & $>320$ & $>64$ \\
\hline 4 & $18 \mathrm{Jul}$ & A & 11 Jul-13 Aug & $\begin{array}{c}\text { K. } \\
\text { pneumoniae }\end{array}$ & Urine & 16 & 132 & $>64$ & $>4$ & 0.5 & 18 & 8 & 2 & 16 & $>128$ & 1 & 20 & $>64$ \\
\hline 5 & $22 \mathrm{Jul}$ & A & 20 Jun-19 Aug & $\begin{array}{c}\text { K. } \\
\text { pneumoniae }\end{array}$ & Urine & 16 & 232 & $>64$ & $>4$ & 0.5 & $>8$ & $>16$ & 4 & 8 & $>128$ & 2 & 1320 & $>64$ \\
\hline 6 & 8 Aug & $\begin{array}{l}E \\
C \\
D\end{array}$ & $\begin{array}{l}25 \text { May-11 Jul } \\
11 \text { Jul-29 Jul } \\
29 \text { Jul-9 Aug }\end{array}$ & $\begin{array}{l}\text { Escherichia } \\
\text { coli }\end{array}$ & Urine & 64 & 132 & $>64$ & $>4$ & 0.5 & $>8$ & $>16$ & 4 & 16 & $>128$ & 0.5 & 1320 & $>64$ \\
\hline
\end{tabular}

AK: amikacin; AMC: amoxicillin/clavulanic acid; CAZ: ceftazidime; CIP: ciprofloxacin; CL: colistin; CTX: cefotaxime; EPM: ertapenem; GM: entamicin; IPM: imipenem; NDM; New Delhi metallo-beta-lactamase; MPM: meropenem; SXT: sulfamethoxazole/trimethoprim; TYG:

tigecyclin; TZP: piperacillin/tazobactam. 
antimicrobial resistance on the management of healthcare-associated infections.

This study reports an outbreak of NDM-producing Enterobacteriaceae colonisation or infection in Italy, where previously there had been only one report of NDM in isolates from two patients, in a different part of the country [5]. As at the time of microbiological diagnosis, the six patients in our study were hospitalised in four different healthcare facilities: epidemiological investigations suggested a likely link between five of the patients (Patients 1-5). For the sixth patient, it was not possible to identify a possible direct link between this patient and all the other patients. Nevertheless, Patient 6 could be the possible source of this outbreak because of the patient's history of previous hospitalisation in New Delhi before admission to a healthcare facility in the Bologna area, where NDM-positive isolates had not been previously reported. We can consequently hypothesise that the NDM-producing bacterial strains were transmitted nosocomially to other patients.

The detection of the NDM-1 gene in five strains of $K$. pneumoniae and one $E$. coli strain confirms that for this resistance mechanism, the risk of spread is not only among clonally related strains of the same species: this gene can also be efficiently spread to other bacterial species. The rapid spread of this gene is not unexpected $[10,11]$ and has been already described among several Enterobacteriaceae species, mainly K. pneumoniae, in the United Kingdom [12]. Further molecular studies are currently in progress in order to better define the correlation between these NDMpositive strains identified in our study.

Given our findings, it will be extremely important to apply strict measures of surveillance and infection control in order to limit the spread of carbapenem-resistance genes in Enterobacteriaceae into other areas of Italy.

\section{References}

1. Walsh TR. Emerging carbapenemases: a global perspective. Int J Antimicrob Agents. 2010;36:S8-14.

2. Struelens MJ, Monnet DL, Magiorakos AP, Santos O'Connor F, Giesecke J; European NDM-1 Survey Participants. New Delhi' metallo-beta-lactamase 1-producing Enterobacteriaceae: emergence and response in Europe. Euro Surveill. 2010;15(46). pii: 19716. Available from: http://www.eurosurveillance.org/ ViewArticle.aspx?Articleld $=19716$

3. Gaibani P, Ambretti S, Berlingeri A, Gelsomino F, Bielli A, Landini MP, Sambri V. Rapid increase of carbapenemaseproducing Klebsiella pneumoniae strains in a large Italian hospital: surveillance period 1 March - 30 September 2010. Euro Surveill. 2011;16(8). pii: 19800. Available from: http:// www.eurosurveillance.org/ViewArticle.aspx?Articleld $=19800$

4. Agodi A, Voulgari E, Barchitta M, Politi L, Koumaki V, Spanakis N, et al. Containment of an outbreak of KPC-3producing Klebsiella pneumoniae in Italy. J Clin Microbiol. 2011;49(11):3986-9.

5. D’Andrea MM, Venturelli C, Giani T, Arena F, Conte V, Bresciani $P$, et al. Persistent carriage and infection by multidrug-resistant Escherichia coli ST405 producing NDM1 carbapenemase: report on the first Italian cases. J Clin Microbiol. 2011;49(7):2755-8.
6. European Committee on Antimicrobial Susceptibility Testing [EUCAST]. Breakpoint tables for interpretation of MICs and zone diameters. 2011. Version 1.3, 5 Jan 2011. Available from: http://www.eucast.org/fileadmin/src/media/PDFs/EUCAST_ files/Disk_test_documents/EUCAST_breakpoints_v1.3_pdf.pdf

7. Clinical and Laboratory Standards Institute (CLSI). Performance standards for antimicrobial susceptibility testing; twenty-first informational supplement. CLSI document M100-S21. Wayne, PA: CLSI; 2011. Available from: http://www.clsi.org/source/ orders/free/m10o-s21.pdf

8. Nordmann P, Poirel L, Carrër A, Toleman MA, Walsh TR. How to detect NDM-1 producers. J Clin Microbiol. 2011;49(2):718-21.

9. BLAST. Bethesda, MD: National National Center for Biotechnology Information. Available from: http://www.ncbi. nlm.nih.gov/BLAST

10. Cornaglia G, Giamarellou H, Rossolini GM. Metallo- $\beta$ lactamases: a last frontier for $\beta$-lactams? Lancet Infect Dis. 2011;11(5):381-93.

11. Nordmann P, Couard JP, Sansot D, Poirel L. Emergence of an autochthonous and community-acquired NDM-1-producing Klebsiella pneumoniae in Europe. Clin Infect Dis. 2011 Sep 29. [Epub ahead of print].

12. Kumarasamy KK, Toleman MA, Walsh TR, Bagaria J, Butt F, Balakrishnan R, et al. Emergence of a new antibiotic resistance mechanism in India, Pakistan, and the UK: a molecular, biological, and epidemiological study. Lancet Infect Dis. 2010;10(9):597-602. 